\title{
LACTANCIA MATERNA UN ALIMENTO INIMITABLE
}

\section{Breastfeeding An Inimitable Food}

\section{EDITORIAL}

\section{Manuel Injante Injante ${ }^{1, a}$}

1. Facultad de Medicina de la Universidad Nacional San Luis Gonzaga de Ica, Perú

a. Pediatra del Hospital Santa María del Socorro de Ica, Perú

La leche materna es el mejor alimento y la mejor bebida que ofrece la naturaleza al individuo, desde su nacimiento; constituye un acto de amor que implica en la madre responsabilidad y esfuerzo para estar a disposición del bebé $(1,2)$.

Aunque la mayoría de los profesionales de la salud parece estar de acuerdo que la lactancia materna es el mejor alimento para las niñas y niños, no todos están capacitados para resolverle a la madre los problemas del amamantamiento. Para poder ayudar a una madre lactante que tenga dudas o problemas, se requiere: Un profundo convencimiento de las ventajas de la lactancia materna, un sitio adecuado, un tiempo suficiente, paciencia, conocimiento sobre lo que se aconseja y mucho respeto por la madre lactante y su hijo (3). En el año 1990 en la Declaración de Inocenti, se establece la estrategia de Protección, Promoción y Fomento de la Lactancia Materna, con el fin de administrar a las niñas y niños una alimentación optima, definida como Lactancia Materna Exclusiva durante los seis primeros meses de vida con la introducción de la alimentación complementaria apropiada y la Lactancia Materna continuada hasta los dos años de edad o más (Lactancia Materna Prolongada) (4).

Desde agosto del 2000 (RM N²40-2000-SA/DM) se ha establecido que la cuarta semana de agosto de cada año, se celebre la Semana de la Lactancia Materna en el Perú. Así mismo a través del tiempo se han reconocido derechos laborales vinculados a la Lactancia Materna, tales como: Licencia pre y pos natal $\left(\mathrm{RL} \mathrm{N}^{\circ} 30312\right.$, Ley $\left.\mathrm{N}^{\circ} 27606\right)$, licencia por Paternidad (Ley $N^{\circ}$ 29409), permiso por lactancia materna, una hora diaria por un año y si el parto es múltiple se incrementa a dos horas diarias (Ley $N^{\circ} 27240$ ), todo centro laboral donde trabajan 20 a más mujeres en edad fértil, debe tener un ambiente privado y cómodo para la extracción y conservación de la leche materna (Ley N²9896) (5).

Las conductas de apego en la madre y la hija o hijo tradicionalmente se han considerado como instintivas, las evidencias científicas han demostrado que la Lactancia Materna forma parte del sistema que prolonga y asegura la protección y la formación de vínculos, lo que incide directamente en el buen desarrollo del sistema nervioso central de la recién nacida o recién nacido. Las evidencias demuestran que apegos seguros se correlacionan con niñas y niños sanos que devienen en adultos sanos, mientras que apegos ansiosos y desorganizados se correlacionan con trastornos en el desarrollo, violencia infantil y procesos psicopatológicos (5).

La leche materna es muy provechosa tanto para la niña y el niño como para la madre. Aumenta la supervivencia infantil, protegiendo al lactante contra las enfermedades diarreicas, la neumonía y otras infecciones potencialmente mortales. Favorece la salud de la madre como es el caso de la prolongación del intervalo entre embarazos y la contribución a protegerla contra los cánceres de ovario y de la mama (6).

La epidemia del SIDA conlleva a un aumento día tras día del número de lactantes que nacen infectados por el VIH. Sin embargo, se ha demostrado que el VIH puede transmitirse a través de la lactancia materna y según estudios se concluye que más de un tercio de los lactantes infectados por el VIH, se infectan a través de la lactancia natural. El riesgo de transmisión
BIBLIOGRAFIA

1. Gonzales C. Un regalo para toda la vida. Guía de Lactancia Materna. Ed. Temas de hoy, 2006

2. Manual de Lactancia Materna. De la teoría a la práctica. Comité de Lactancia Materna de la Asociación Española de Pediatría. Ed. Panamericana, 2006.

3. Consejería en lactancia materna. Curso de capacitación - Unicef (internet), se encuentra en htt/ps://www.unicef.org/el salvador/consejería en_lactancia_materna.pdf.

4. Norma técnica de Lactancia Materna - Minsa. (Internet). Se encuentra en $\mathrm{fp}: / / \mathrm{ftp} 2$.minsa.gob.pe.

5. RM. N²40-2000SA/DM. MINSA. Semana de la lactancia materna.

6. Pérez-Escamilla R. Influencia de la lactancia materna en el desarrollo psicosocial. (Internet). Se encuentra en http://www.enciclopedia-infantes.com/lactancia materna/segúnlosexpertos/influencia_de_la_lactancia_materna_en_el_desarrollo_psicosocial. 7. OMS. EI VIH y la alimentación del lactante. Salud de la madre, el recién nacido, el niño y del adolescente. (Internet). Se encuentra en: www.who. Int/maternal_child_adolescent/topics/newborn/nutrition/hivif/12/.

\section{CITAR COMO:}

Injante Injante Manuel.

Lactancia materna un alimento inimitable. Rev med panacea. 2017 May-Ago; 6 (2): 44 - 45 
durante la lactancia materna es acumulado, cuanto más tiempo da el pecho una madre infectada por el VIH, más se incrementa el riesgo de transmisión a través de la lactancia. Actualmente la Organización Mundial de la Salud, para reducir el riesgo de transmisión del VIH a lactantes y a la vez, minimizar el riesgo de otras causas de morbilidad y mortalidad, recomienda que las madres VIH - positivas, eviten toda forma de lactancia materna y utilicen sustitutos de la leche materna, siempre y cuando esto sea aceptable, factible asequible, sostenible y seguro; pero también hay otras opciones como la Lactancia Materna Exclusiva con interrupción temprana y otras opciones de leche materna como leche de nodrizas, leche materna extraída y tratada con calor y bancos de leche materna (7). 